\title{
Heart Failure: An Overview of Morbidity and Mortality in Rio Grande do Sul
}

\author{
Carolina Zenilda Nicolao, ${ }^{1}$ J Juliana Bischoff Ferreira, ${ }^{1}$ Adriana Aparecida Paz, ${ }^{10}$ Graciele Fernanda da Costa \\ Linch, $^{10}$ Marciane Rover, ${ }^{2}$ Emiliane Nogueira de Souza ${ }^{1,2}$ \\ Universidade Federal de Ciências da Saúde de Porto Alegre (UFCSPA), 'Porto Alegre, RS - Brazil \\ Instituto de Cardiologia - Fundação Universitária de Cardiologia do $R S,{ }^{2}$ Porto Alegre, $R S$ - Brazil
}

\section{Abstract}

Background: Heart failure (HF) is the final pathway of most cardiac diseases. Although the prevalence of HF has increased, due to the ageing of the population, more comprehensive data have shown a reduction in the percentage of HF hospital admissions over the last years.

Objective: Assess the morbidity and mortality of HF patients in Brazil, Rio Grande do Sul and Porto Alegre.

Method: The study is a retrospective analysis of data from the Brazilian Unified Health System's (Sistema Único de Saúde [SUS]) Department of Informatics (DataSUS). We evaluated the incidence of HF hospital admissions, the average length of stay, hospital costs and sex ratio, during a ten-year period (2007 to 2016). Due to availability of the system, mortality rate and age range, the total duration of the study was nine years.

Results: Within this period, the percentage of hospitalizations for HF decreased. On the other hand, the length of stay increased in all regions studied. Mortality rates were in decline in all regions. Hospital costs showed an increase of $110.8 \%$. HF was more prevalent in patients between the seventh and eighth decades of life, with men being more affected than women, except in Rio Grande do Sul.

Conclusion: We conclude that, in spite of the high costs of HF to healthcare providers, hospitalizations and mortality rates have shown a significant decline over the last years, which results from the advances in the treatment of this disease, through initiatives to improve patient education, engagement and planning in health care and self-care. (Int J Cardiovasc Sci. 2019;32(6):596-604)

Keywords: Heart Failure/physiopathology; Aging; Hospitalization; Plans Health; SUS- Unified Health System; Mortality; Morbidity.

\section{Introduction}

Heart failure is a burden for public health worldwide due to high mortality, readmission rates and considerable costs to healthcare services. ${ }^{1}$ About $30 \%$ of patients need rehospitalization within 60 to 90 days. ${ }^{2} \mathrm{HF}$ is increasing in prevalence around the world as a result of population ageing. The projections indicate that by $2030,46 \%$ of the population will be affected by $\mathrm{HF}^{3}$ In relation to the expenses, HF admissions accounted for $2.3 \%$ of the amount spent on healthcare services in Brazil in 2017. ${ }^{4}$

Although HF prevalence has increased, analysis of more comprehensive data on the situation of HF hospitalizations in Brazil, using data from DATASUS, showed a decrease in mortality rates in Brazil, especially in the South and Southeast regions. ${ }^{5}$ This phenomenon seems to reflect an evolution in the treatment of the disease, including low-cost initiatives to improve treatment recommendations, patient education, engagement and post-discharge planning. ${ }^{2}$ The impact of HF is expected to increase substantially, as a result of increased survival of CAD patients, in combination with population ageing. ${ }^{6,7}$ This raises the need for registers to project, conduct and better understand this population of heterogeneous patients.

The BREATHE study presented data related to the South and Southeast regions of Brazil. The study analyzed the data from five centers in the South region, where 172 
patients were followed. This follow-up showed that the population affected by HF in the South region is older and the ischemic etiology predominates. ${ }^{8}$ However, few studies have considered the morbidity and mortality due to HF in Rio Grande do Sul. This prevents a more comprehensive analysis of HF treatment and outcomes in that region. Nowadays, Rio Grande do Sul has large academic centers linked to hospital institutions, where publications related to the area of Cardiology are among the most published topics.

In this perspective, identifying the scenario of morbidity and mortality due to HF over the last years justifies and aids the planning and monitoring of actions focused on the patient, in the context of initiatives that aims at health promotion and reduction of readmissions. Thus, the objective of this study was to assess the evolution of morbidity and mortality in adult HF patients in Brazil, specifically in the state of Rio Grande do Sul and its capital Porto Alegre.

\section{Method}

This is a serious retrospective analysis, performed using public domain data. The scenario of the study is composed of the database of the Brazilian Unified Health System's (Sistema Único de Saúde [SUS]) Department of Informatics (DataSUS). The variables selected from the database were: regions (Brazil, Rio Grande do Sul and Porto Alegre), in-hospital morbidity (ICD-10 morbidity list, diseases of the circulatory system, heart failure (ICD-I50), mortality (proportional mortality), age range, average cost per admission, average length of stay and sex ratio. The ICD-10 included corresponds to the main Hospital Admission Authorization $(\mathrm{AIH})$, in which the information on the reason for hospital admission is provided. The variables selected were collected from January 2007 to December 2016 and gathered in November 2017. Proportional mortality is the measure of importance of a specific cause of death in relation to all causes of death within the same population group.

The temporality (2007 to 2016) was defined in virtue of the availability of the data on DATASUS. The use of data from 2007 was intentional because, in the previous 10 years, multiprofessional follow-up strategies were assessed and implemented in that region. With the exception of the variables age range and mortality, temporal delimitation occurred from January 2008 to December 2016 and January 2007 to December
2015, respectively, due to unavailability of the system consulted (DATASUS).

The collection of these variables allowed for crosschecking of data, which were saved in the .csv format. Data analysis was temporal, through secondary data, which were organized in a new Microsoft Excel spreadsheet to enable descriptive statistics and graphical analysis.

Because this study deals with secondary data published by the Brazilian Ministry of Health (MS), there was no need for submission to the Research Ethics Committee, but all ethical precepts were followed according to the Resolution 466/2012, of the National Health Council. ${ }^{9}$

\section{Results}

Data will be presented according with the variables analyzed, and the percentages of HF admissions will be shown, followed by length of stay, cost, mortality, age range and sex. All variables will be considered by time series in accordance with the three regions studied.

Figure 1 shows the percentages of HF admissions from the total number of admissions due to diseases of the circulatory system. We can observe that, during the period investigated, there was a decrease in the percentages of admissions in the three regions. Moreover, we must highlight that the percentages for Porto Alegre are lower than those for RS and Brazil, where percentage change showed a decrease of $15 \%, 24 \%$ and $25 \%$, respectively.

Considering age range, patients in their seventies had more hospitalizations in Brazil and in RS. In Porto Alegre, on the other hand, higher hospitalization percentages were observed in patients in their sixties, as shown in Figure 2.

When the sex ratio is calculated (males per 100 women), in which a ratio of 100 means there are equal numbers of males and females, if the ratio is above 100 , it means there are more males than females; whereas a sex ratio below 100 indicates that there are more females than males. HF admission rates were higher among males, considering the data related to Brazil and Porto Alegre, where the sex ratio was of 117 males per 100 females admitted due to HF in 2016. On the other hand, in Rio Grande do Sul, there was a prevalence of women, with a ratio of 91 males per 100 females (Figure 3).

The average length of stay due to HF in Brazil was 6.1 days in 2007, reaching 7.4 in 2016, a percentage change 
30,00

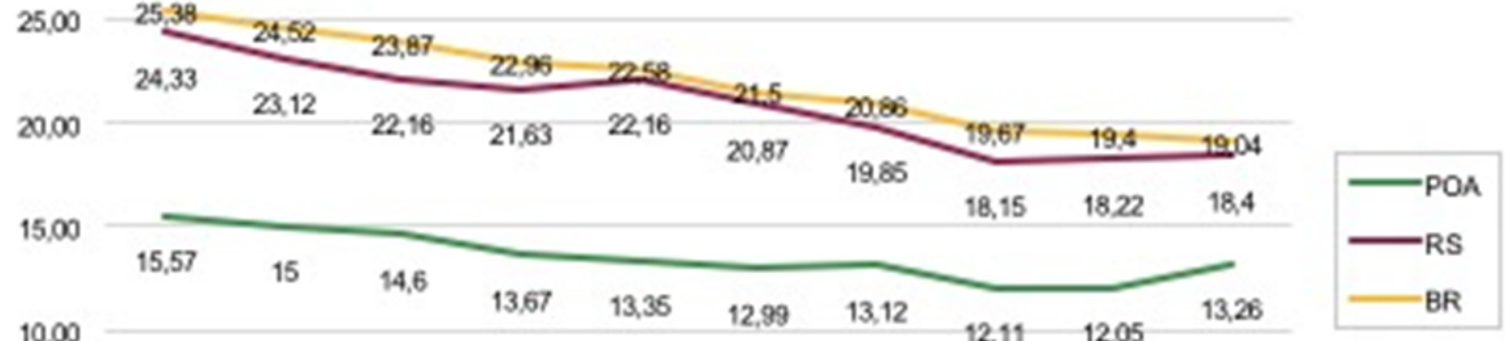

5.00

0,00

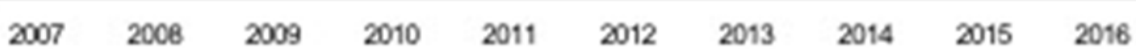

Figure 1 - Percentages of admissions for diseases of the circulatory system in Brazilian Unified Health System's (Sistema bnico de Sazde [SUS]) due to HF in the period from 2007 to 2016 in Brazil, Rio Grande do Sul (RS) and Porto Alegre (POA).

Source: Elaborated by the author based on data obtained from DATASUS (2017).

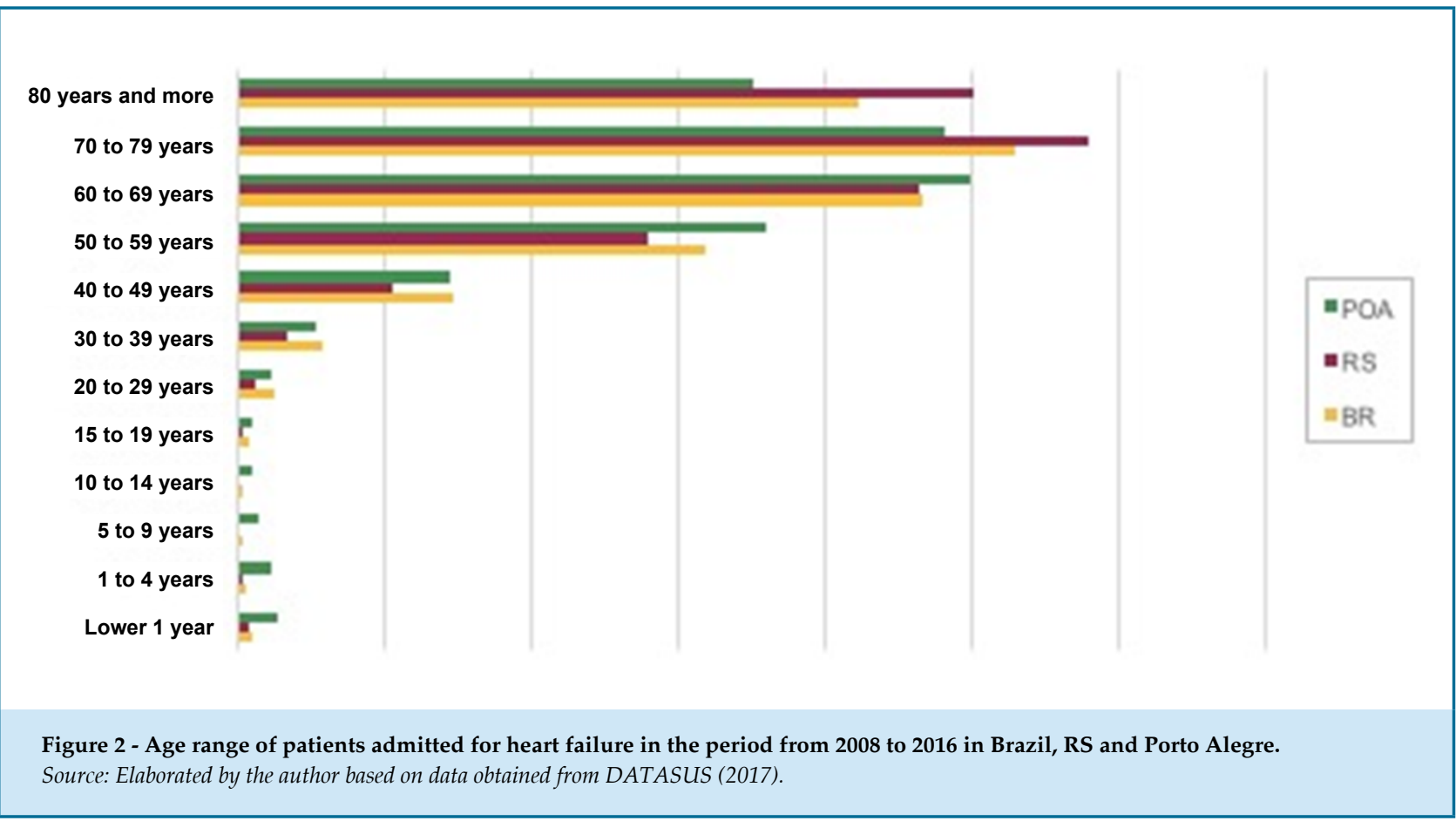

increase of $21 \%$, whereas in Rio Grande do Sul, the hospital length of stay, in 2007, was 6.7 days and, in 2016, 7.5 days - a percentage change of $12 \%$. In Porto Alegre, the average length of stay was 10.10, in 2007, and 10.06 days, in 2016, in which the percentage change was 5\%. (Figure 4). 

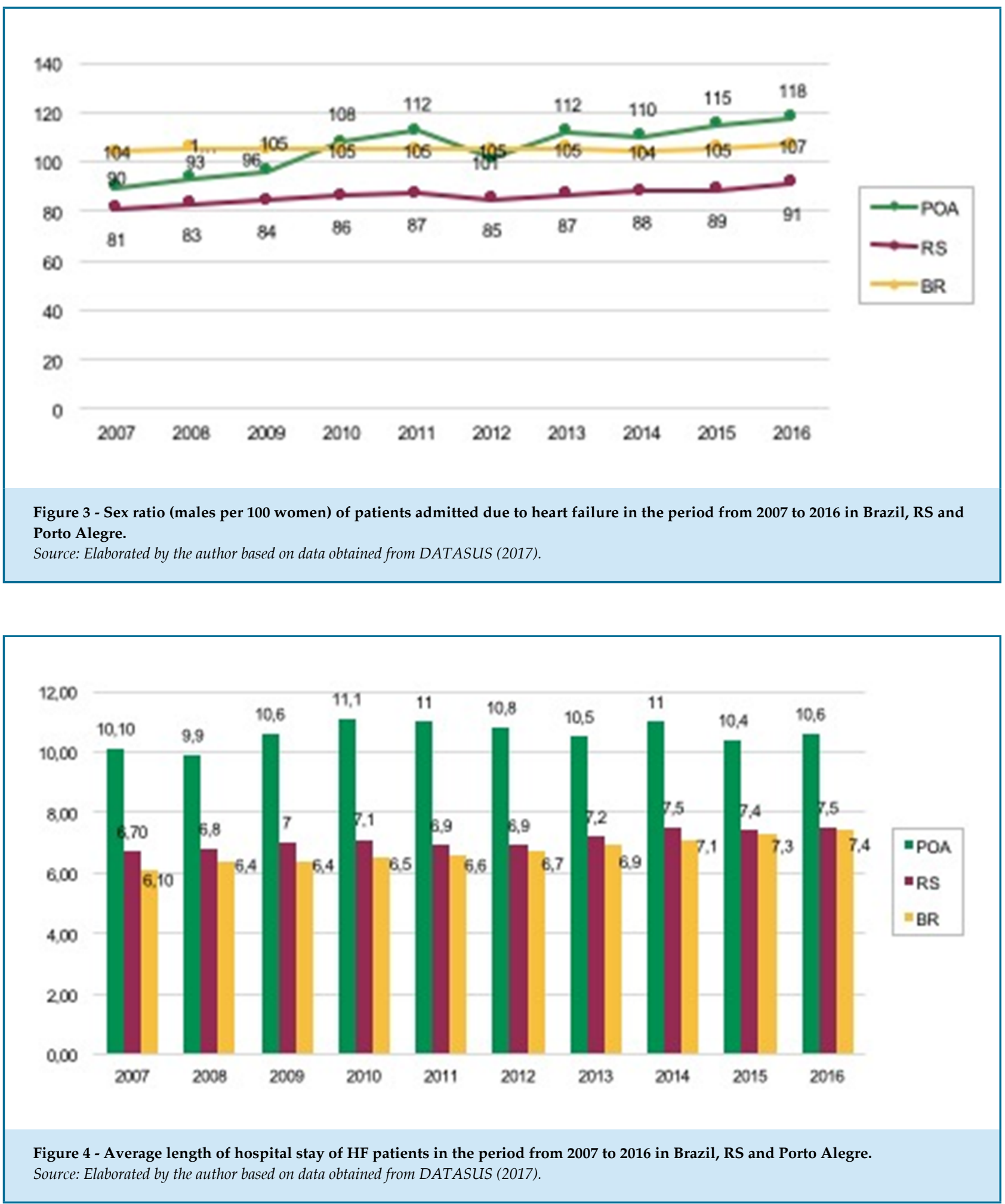

In relation to hospitalization costs, the average value per hospitalization was initially $\mathrm{R} \$ 739.39$, in 2007 , reaching $R \$ 1,559.08$ in 2016 in Brazil, with a percentage change increase of $97 \%$. The corresponding values for
Porto Alegre are higher in relation to the values found in the other regions, in which the initial value was $\mathrm{R} \$$ $1,047.74$, in 2007, increasing to $\mathrm{R} \$ 2,464.47$, in 2016, with a percentage change increase of $135 \%$ (Figure 5). 


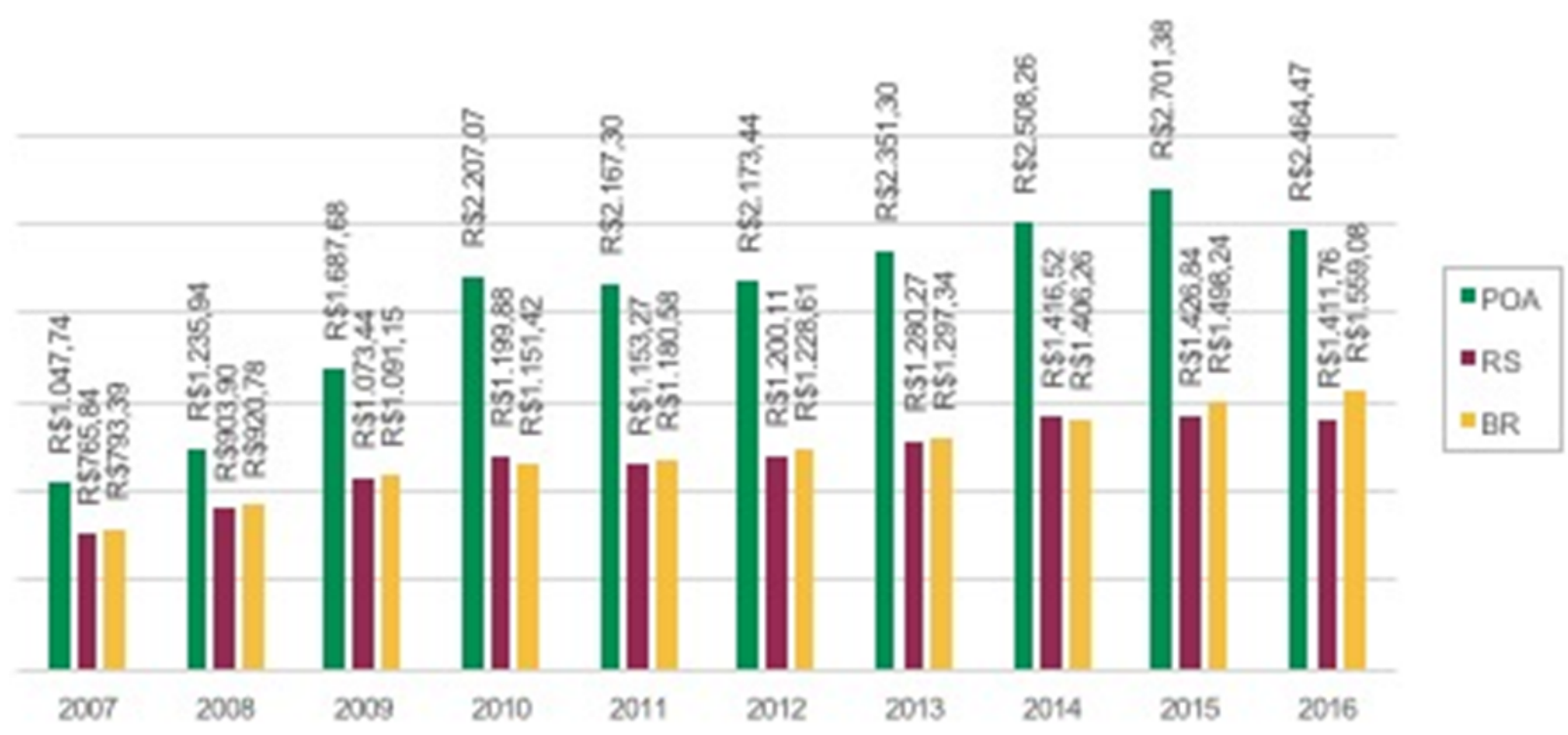

Figure 5 - Mean per-patient cost of an HF-related hospitalization in the period from 2007 to 2016 in Brazil, RS and Porto Alegre. Source: Elaborated by the author based on data obtained from DATASUS (2017).

In the assessment of proportional mortality due to heart failure, all regions studied showed a reduction in in-hospital mortality. Rio Grande do Sul and Brazil showed a decrease in mortality rates to $25 \%$ and $19 \%$, respectively. A more significant decrease was observed in Porto Alegre, where the percentage change reduced to $61 \%$, during the period studied, as shown by Figure 6 .

\section{Discussion}

This study presents an overview of the morbidity and mortality due to heart failure in the Unified Health System, over a 10-year period in Brazil, in Rio Grande do Sul and Porto Alegre. This overview shows, in general terms, a decrease in admissions and mortality rates due to heart failure over the years. Even though Porto Alegre has the longest length of hospital stay and, therefore, higher costs, it still presents the lowest admission rates and less mortality. The age range followed a similar trend in all regions. Finally, it is worth to mention that, over time, more men than women have been affected by HF, since there was a male predominance in two out of the three regions studied.

As for the percentage of admissions for diseases of the circulatory system, a decrease in HF hospitalizations was observed in Brazil in the period studied. This data suggests that the treatment of HF patients has been effective in the national territory. However, the BREATHE study shows that there is a considerable gap in HF treatment in Brazil, since treatments do not follow the guidelines currently published. ${ }^{8}$ On the contrary, the decrease in the percentage of admission has an impact on the aspects that characterize HF as a chronic disease with high morbidity and mortality, since the decrease in admissions expresses an improvement in the assistance provided to the patients in the last years.

Similarly, data from Rio Grande do Sul and Porto Alegre suggest that local institutions are in consonance with the latest guidelines published. In addition, greater population access to medication and patient education about drug and non-drug treatment may explain the decrease in hospitalizations over the years. It is well known that adherence to treatment has an impact on the prognosis of HF patients. ${ }^{10}$

A previous study that assessed admissions for HF through the Global Health database and the World Health Organization (WHO) database showed that admissions due to HF account for $2.9 \%$ of admissions in developing countries, including Brazil. In low-income countries, $\mathrm{HF}$ admissions account for $31 \%$ of hospitalizations in public healthcare. ${ }^{11}$ A previous study that assessed HF admissions for 12 years in Brazil reported that, even 


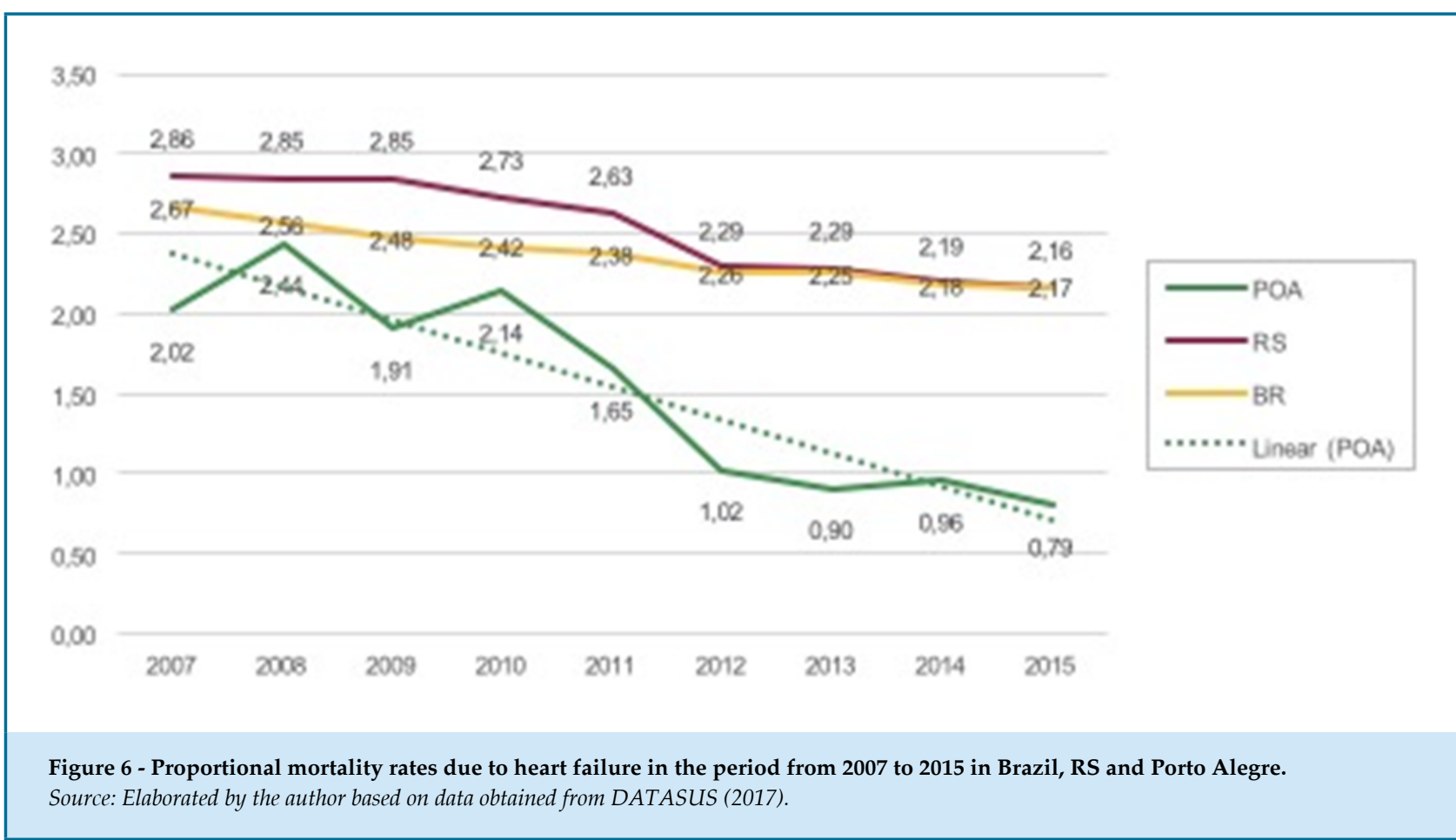

though there was a decrease in HF hospitalizations in absolute numbers and a decrease in the relation of HF admissions and total admissions, the average length of stay and the mortality rate increased over time. ${ }^{10}$

Despite the predominant age range, the I Brazilian Registry of Heart Failure (BREATHE) reported a mean age of 64 years, with $73 \%$ of patients above the age of 75 years, in patients admitted with acute HF. ${ }^{8}$ The same study showed a variation in the mean age in relation to Brazilian regions, with patients showing higher ages in the South and Southeast regions compared to patients in the North region (on average, 59 years of age)..$^{8-12}$ Similarly, a pioneer study that portrayed the epidemiological profiles of patients admitted for decompensated HF between public and private hospitals in the city of Niterói, Rio de Janeiro, reported a mean age of 61.1 years in public hospitals. ${ }^{13}$ Other studies published recently indicate a predominance of individuals in the eighth decade of life (70-79 years of age)..$^{10,14,15}$

Advanced age patients account for a significant fraction of the sample studied. ${ }^{8}$ In Porto Alegre, the greatest number of $\mathrm{HF}$ admissions occurred in patients within the age range of 60 to 69 years. Data from Porto Alegre are similar to those from an international multicenter trial designed to assess HF patients in 388 centers in North America, Europe, Latin America and Asia, in which the mean age was 67 years. ${ }^{16}$ In two previous studies that assessed HF patients in low-income countries, the mean age was 52 to 59 years. ${ }^{11,17}$ Regional variation in age may be explained by differences in the prevalence of underlying risk factors, as well as living standards. ${ }^{18}$

It is estimated that HF will increase by $46 \%$ from 2012 to 2030, resulting in more than 8 million people over 18 years of age with HF. This ascending prevalence is a result of the growth in life expectancy, since HF affects mainly the elderly. ${ }^{8}$

Men have higher hospitalization rates for $\mathrm{HF}$ according to data from previous studies. ${ }^{10,13,14,16,19}$ In this study, we observed a higher prevalence of males in all regions of Brazil and Porto Alegre. On the other hand, in Rio Grande do Sul, the sex ratio indicates an inversion, with a predominance of women, similar to a study carried out in a city of the state of Minas Gerais (Brazil), in which women accounted for $51 \%$ of admissions, in the period from 2010 to $2014 . .^{20}$ Similarly, a previous study performed in public and private hospitals in the city of Niterói (Rio de Janeiro) reported $51 \%$ of female hospitalizations in private hospitals. ${ }^{13}$ Analysis of global registries of HF patients indicated that $40 \%$ to $50 \%$ of $\mathrm{HF}$ patients are females, a group of patients traditionally under-represented in previous clinical trials. This is a remarkable observation, since female patients are unique in that they tend to be older at the time of initial diagnosis 
and are more likely to have heart failure with preserved ejection fraction (HFpEF). ${ }^{18}$ A previous study that assessed HF patients, according to age groups, showed an inversion in prevalence after the seventh decade of life, with a female prevalence. This fact can be explained due to women's higher life expectancy compared to men. ${ }^{10}$

The Ministry of Health attributed the higher rates of admissions among men to their greater vulnerability to diseases, especially to severe and chronic illnesses, and to the fact that they die earlier than women do. Regardless of the higher vulnerability and elevated mortality rates, men do not search for basic healthcare services, in the same proportion as momen. ${ }^{21}$

In relation to the length of stay, this study showed an increase in the period of hospitalization of HF patients, and the most expressive increase occurred in Brazil, with a variation of $21 \%$. A previous study that assessed the average length of stay of adult HF patients in the National Health Service (SUS) in Brazil reported an average length of stay of 5.8 days, in 2001, reaching 6.6 days, in 2012, which represents an increase of $12.12 \% .{ }^{9}$ However, a study carried out in Niterói (Rio de Janeiro), in 2001, reported an average length of stay of 12.6 days in public hospitals and 8 days in private hospitals. ${ }^{13}$ Similar data were found in previous global studies, reporting an average length of stay of 5 to 6 days in North America, Asia and Argentina. ${ }^{11,18,22}$

The present study found similar data, showing an increase in the length of stay in Brazil and RS. In Porto Alegre, we observed an increase in average length of stay throughout the period studied. This can be attributable to the higher number of hospitals and a greater offer in specialized centers and institutions linked to universities with a focus on teaching and research, providing qualified service in accordance with current guidelines, as well as a clear decrease in mortality rates, especially in Porto Alegre. Data equivalent to those from Porto Alegre are reported in previous studies, indicating 10 days of hospitalization in Western and Eastern Europe and low-income countries. ${ }^{11,18}$

Even with technological advances in the treatment of $\mathrm{HF}$ and in spite of the reduction in hospitalization rates, the average length of stay and hospital costs have increased, probably as a result of patients' clinical complexity..$^{10}$ A previous study that assessed the costs of heart failure-related hospitalizations in Brazil for 12 years showed a $132.8 \%$ increase in hospitalization costs in the period studied. The data obtained from this study also indicate an increase in the average cost per hospital admission. In Porto Alegre, the values are higher compared to the other regions studied, throughout the period considered, with a $135.2 \%$ increase in cost per hospitalization. These data should be correlated with the length of hospital stay, the percentage of admissions and mortality rates, which show an increase in length of stay and a decrease in admissions and mortality rates. Thus, we can conclude that the assistance provided to patients is related to better current practices, since in Porto Alegre patients had better clinical outcomes.

In 2016, in Brazil, the costs of HF-related hospitalizations were $\mathrm{R} \$ 334$ million, accounting for $2 \%$ of total hospitalization costs. For this reason, there is an increasing search for the implementation of prophylactic and preventive measures. ${ }^{14}$

In relation to mortality rates, a multicenter analysis performed in Brazil (BREATHE), showed that low treatment adherence accounts for a significant increase in morbidity, mortality and hospital costs. ${ }^{8}$ However, the data obtained from this study show a decrease in inhospital mortality rates throughout the 10 years studied. Porto Alegre showed a $61 \%$ decrease in mortality rates. Similarly, Brazil and Rio Grande do Sul had a decrease of $24.5 \%$ and $19 \%$, respectively.

A previous study that assessed HF-related mortality in Brazil showed a $41 \%$ increase in mortality in the period from 2001 to $2012 .{ }^{10}$ This increased mortality rate was associated with patient severity and with the fact that many patients with heart failure are elderly. Nevertheless, the data obtained from this study show a decrease in mortality due to HF, which can be attributable to the advances in treatment over the last years. It is well known that the use of proper medication, in combination with non-pharmaceutical measures, such as multidisciplinary follow-up and monitoring, provide significant benefits to clinical prognosis and consequently decreased morbidity and mortality.

Analysis of the results of the BREATHE study showed that $63 \%$ of the patients received guidelines on hospital discharge about the correct use of medications, whereas only $34.9 \%$ were advised about the diet to be followed at home and $16 \%$ were counseled about physical activity. ${ }^{8}$

It is well known that lack of adherence to pharmacological and non-pharmacological treatment are among the reasons for decompensated HF and consequent hospitalization. ${ }^{13,19,23}$ In this context, followup by a multi-professional team after hospital discharge 
is recommended to reduce morbidity and mortality and improve quality of life for HF patients. The aim of multidisciplinary management is to strengthen a health care system that provides a network of services for patients, in both hospital and ambulatory care settings. Disciplinary management programs are intended to improve the results through structured follow-up and patient education. ${ }^{24}$ Educational programs are an important tool to improve the management of selfcare by the multi-professional team specialized in the follow-up of patients with HF. However, it is difficult to identify the appropriate strategies and scenarios, since the interventions are heterogeneous, as well as the number of professionals involved, hindering the evaluation of results. ${ }^{25}$

It is important to mention that, because the data were collected from Hospital Admission Authorization (AIH) forms, through the DATASUS system, the assessment of other factors that can influence or clarify the causes of decompensation of HF that led to hospital admission were not analyzed due to limitations of the system.

\section{Conclusions}

The data presented showed the prevalence of heart failure-related hospitalization in the Brazilian Unified Health System (SUS), in RS and its capital, compared to national data. We observed a reduction in admission and mortality rates due to HF in all regions studied. The average length of hospital stay and hospital costs increased significantly over the period analyzed. Hospitalizations are prevalent among elderly in the seventh and eighth decades of life. Heart failure is a disease that affects both sexes, whose prevalence depends on the region studied. This is a timely moment to review the current management and to implement evidence-

\section{References}

1. Li X, Chen C, Qu MY, Li Z, Xu Y, Duan XF, et al. Perceptions and acceptability of receiving SMS self-care messages in chinese patients with heart failure: an inpatient survey. J Cardiovasc Nurs. 2017;32(4):357-64

2. Cowie MR, Lopatin YM, Saldarriaga C, Fonseca C, Sim D, Magaña JA, et al. The optimize heart failure care program: initial lessons from global implementation. Int J Cardiol. 2017;(236):340-4.

3. Creber RM, Patey M, Lee CS, Kuan A, Jurgens C, Riegel B. Motivational interviewing to improve self-care for patients with chronic heart failure: MITI-HF randomized controlled trial. Patient Educ Couns. 2016;99(2):256-64 based measures in a controlled and monitored setting. Similarly, initiatives should be undertaken to improve quality of continuity of care.

\section{Author contributions}

Conception and design of the research: Nicolao CZ, Paz AA, Linch GFC, Rover M, Souza EN. Acquisition of data: Nicolao CZ, Ferreira JB, Paz AA, Linch GFC. Analysis and interpretation of the data: Nicolao $\mathrm{CZ}$, Ferreira JB, Paz AA, Linch GFC, Rover M, Souza EN. Statistical analysis: Nicolao CZ, Paz AA, Linch GFC, Souza EN. Obtaining financing: Nicolao CZ. Writing of the manuscript: Nicolao CZ, Ferreira JB, Paz AA, Linch GFC, Rover M, Souza EN. Critical revision of the manuscript for intellectual content: Nicolao $\mathrm{CZ}$, Linch GFC, Rover M, Souza EN.

\section{Potential Conflict of Interest}

No potential conflict of interest relevant to this article was reported.

\section{Sources of Funding}

There were no external funding sources for this study.

\section{Study Association}

This article is part of the thesis of master submitted by Carolina Zenilda Nicolao, from Universidade Federal de Ciências da Saúde de Porto Alegre (UFCSPA).

\section{Ethics approval and consent to participate}

This article does not contain any studies with human participants or animals performed by any of the authors.
4. Machado W, Vieira MC, Marino P. Tópicos sobre exercício físico e insuficiência cardíaca: miopatia e caquexia na origem da intolerância ao esforço. Rev DERC. 2017;23(1):12-5.

5. Brasil. Ministério da Saúde. Datasus.Departamento de informática do SUS (DATASUS). Estrutura. [Internet]. [citado 2018 jan 11] Disponível em: http:/ / datasus.saude.gov.br/ datasus/estrutura.

6. Rosa ACM, Lamari NM. Caracterização de pacientes reinternados no setor de cardiologia. Arq Ciênc Saúde. 2017;24(3):79-83.

7. Fonseca C, Brás D, Araújo I, Ceia F. Heart failure in numbers: estimates for the 21st century in Portugal. Rev Port Cardiol. 2018;37(2):97-104. 
8. Albuquerque DC, Souza Neto JD, Bacal F, Rohde LEP, BernardezPereira S, Berwanger $\mathrm{O}$, et al. I brazilian registry of heart failure - clinical aspects, care quality and hospitalization outcomes. Arq Bras Cardiol. 2015;104(6):433-42.

9. Brasil. Ministério da Saúde. Conselho Nacional de Saúde (CNB). Resolução $n^{\circ} 466$, de 12 de dezembro de 2012. [Internet]. [citado 2018 jan 11] Disponível em: http: / / conselho.saude.gov.br/resolucoes / 2012 / reso466.pdf.

10. Kaufman R, Azevedo VMP, Xavier RMA, Geller M, Chaves RBM, Castier MB. Evolution of heart failure-related hospital admissions and mortality rates: a 12-year analysis. Int J Cardiovasc Sci. 2015;28(4):276-81.

11. Callender T, Woodward M, Roth G, Farzadfar F, Lemarie JC, Gicquel S, et al. Heart failure care in low and middle-income countries: a systematic review and meta-analysis. PLoS Med. 2014;11(8):e1001699.

12. Dokainish H, Teo K, Zhu J, Roy A, AlHabib KF, ElSayed A, et al. Global mortality variations in patients with heart failure: results from the International Congestive Heart Failure (INTER-CHF) prospective cohort study. Lancet Glob Health. 2017;5(7):e665-72

13. Tavares LR, Victer H, Linhares JM, Barros CM, Oliveira MV, Pacheco LC, et al. Epidemiology of decompensated heart failure in the city of Niterói - EPICA - Niterói Project. Arq Bras Cardiol. 2004;82(2):121-4.

14. Reis APM, Souza AG, Ferreira GCO, Oliveira JMR, Venancio JC, Fernandes TM, et al. Prevalence of heart failure in Brazil: a problem of public health. Rev Educ Saúde. 2016;4(2):24-30

15. Pariona M, Saldaña PAS, Reyes MP, Villanes JSR, Contreras MJ, Valenzuela-Rodríguez G. Epidemiological clinical characteristics of acute cardiac insufficiency in a tertiary hospital in Lima, Peru. Rev Peru Med Exp Salud Publica. 2017;34(4):655-9.

16. Howlett JG, Ezekowitz JA, Podder M, Hernandez AF, Diaz R, Dickstein $\mathrm{K}$, et al. Global variation in quality of care among patients hospitalized with acute heart failure in an international trial: findings from the acute study clinical effectiveness of nesiritide in decompensated heart failure trial (ASCEND-HF). Circ Cardiovasc Qual Outcomes. 2013;6(5):534-42.

17. Dokainish H, Teo K, Zhu J, Roy A, Al-Habib K, ElSayed A, et al. Heart failure in low- and middle-income countries: background, rationale, and design of the INTERnational Congestive Heart Failure Study (INTERCHF). Am Heart J. 2015;170(4):627-34.

18. Ambrosy AP, Fonarow GC, Butler J, Chioncel O, Greene SJ, Vaduganathan $\mathrm{M}$, et al. The global health and economic burden of hospitalizations for heart failure: lessons learned from hospitalized heart failure registries. J Am Coll Cardiol. 2014;63(12):1123-33.

19. Rabelo ER, Aliti GB, Linch GFC, Sauer JM, Mello AMFS, Martins SM, et al. Non-pharmacological management of patients with decompensated heart failure: a multicenter study - EMBRACE. Acta Paul Enferm. 2012;25(5):660-5

20. Borges NLC, Ferreira TN, Prates SFL, Dantas IKC, Souto LDP, Pereira JA. Profile of morbidity caused by heart failure in the city of Montes Claros by DATASUS. Rev Eletr Acervo Saúde. 2017;Suppl 5:S256-61.

21. Nascimento WO, Santos AMR, Ribeiro IP, Oliveira ADS. Profile of elderly people with heart failure in an emergency hospital. Cogitare Enferm. 2016;21(4):1-10.

22. Greene SJ, Fonarow GC, Solomon SD, Subacius H, Maggioni AP, Böhm $\mathrm{M}$, et al. Global variation in clinical profile, management, and postdischarge outcomes among patients hospitalized for worsening chronic heart failure: findings from the ASTRONAUT trial. Eur J Heart Fail. 2015;17(6):591-600

23. Bonin CDB, Santos RZ, Ghisi GLM, Vieira AM, Amboni R, Benetti M. Construction and validation of a questionnaire about heart failure patients' knowledge of their disease. Arq Bras Cardiol. 2014;102(4):364-73.

24. Ponikowski P, Voors AA, Anker SD, Bueno H, Cleland JGF, Coats AJS et al. 2016 ESC guidelines for the diagnosis and treatment of acute and chronic heart failure: the task force for the diagnosis and treatment of acute and chronic heart failure of the European Society of Cardiology (ESC) developed with the special contribution of the Heart Failure Association (HFA) of the ESC. Eur Heart J. 2016;37(27):2129-200.

25. Arruda CS, Pereira JMV, Figueiredo LS, Scofano BS, Flores PVP, Cavalcanti ACD. Effect of an orientation group for patients with chronic heart failure: randomized controlled trial. Rev Lat Am Enfermagem. 2017;25:e2982. 